\title{
Sobre o cuidar e o ser cuidado na atenção domiciliar
}

\author{
About caring and being cared for in home care
}

Sandra Maria Luciano Pozzoli1, Luiz Carlos de Oliveira Cecílio²

RESUMO O objetivo deste artigo é evidenciar experiências do cuidar e ser cuidado e apresentar a visão de cuidadores familiares sobre um Serviço de Atenção Domiciliar. É um estudo de caso que aplica a cartografia como ethos no campo de pesquisa para captar as experiências durante as visitas domiciliares e entrevistas com cinco cuidadoras. Para análise da dimensão empírica, foram eleitos Planos de Corte e, dentro destes, Planos de Visibilidade para exercício da reflexividade. A alteridade vivida pelos cuidadores e a sobrecarga de responsabilidades são algumas expressões captadas no campo de pesquisa que indicam a necessidade de associar serviços de saúde a serviços de apoio sociais.

PALAVRAS-ChAVe Serviços de assistência domiciliar. Assistência domiciliar. Cuidadores. Serviços domésticos.

ABSTRACT The purpose of this article is to highlight experiences of caring and being cared of and present the perspective of family caregivers about a Home Care Service. It is a case study that applies the cartography as ethos in the research field to capture experiences during home visits and the interviews with five caregivers. The empirical research analysis used Cutting Plans, of which Visibility Plans were applied as for reflexivity exercise. Otherness lived by caregivers and their responsibility overload are some expressions captured in the field of research that reveals the need to associate health services with social support services.

KEYWORDS Home care services. Home nursing. Caregivers. Homemaker services.

1 Universidade Federal de

São Paulo (Unifesp) - São Paulo (SP), Brasil.

sandrapozzoli@gmail.com

2 Universidade Federal de São Paulo (Unifesp) - São Paulo (SP), Brasil.

luizcecilio60@gmail.com 


\section{Introdução}

A dependência de cuidados por longo prazo no ambiente domiciliar e a dedicação de cuidadores a essas pessoas dependentes têm sido objeto de estudo de vários pesquisadores, que revelam as diversas dificuldades associadas ao cuidar, atividade quase sempre exercida de modo solitário.

Pesquisas revelam que de $83,1 \%$ (GAIOL); FUREGATO; SANTOS, 2012) a $93,4 \%$ dos cuidadores são mulheres (FELGAR, 2004). Desde a pesquisa de Karsch (2004), realizada no início da década de 1990, há a constatação de que os cuidadores estão em casa, cuidando de seus familiares com dependência, sem quase nenhuma orientação e, em sua maioria, estão sozinhos nas tarefas de cuidado.

Segundo Cruz et al. (2010), Muniz et al. (2016) e Gutierrez, Fernandes e Mascarenhas (2017), dentre as dificuldades listadas por cuidadores estão os conflitos familiares, a cobrança da sociedade, o desconhecimento sobre patologias que acometem o doente e técnicas inerentes ao cuidado, falta de colaboração do paciente, falta de recursos econômicos, dentre outras contrariedades levantadas em relação ao mundo do cuidar.

Felgar (2004) revelou que 39,6\% dos cuidadores questionados em sua pesquisa informaram sensação de desamparo e relacionaram esse sentimento à doença do paciente.

Em grande parte do mundo, as pessoas estão envelhecendo e, mesmo com todo o arcabouço de informações sobre a melhor maneira de manter a saúde por mais tempo ou a qualidade de vida, chega o momento em que precisamos ser cuidados por outras pessoas, as quais, em grande parte das culturas, são familiares ou amigos.

O cuidador assume, portanto, responsabilidades de cuidados no domicílio em que seriam realizados pela equipe de saúde se a pessoa doente dependente de cuidado de longo prazo estivesse internada no hospital. Dessa forma, a atenção domiciliar como modelo assistencial possibilita que o cuidado seja realizado em espaço conhecido, com significado afetivo para a pessoa doente e que, minimamente, preserva certa autonomia do doente (LACERDA, 2010).

Para Agich (2008, P. 32-33), a autonomia é "irremediavelmente dependente do contexto". O autor considera que para se tentar desenvolver uma definição de autonomia deve-se tomar como ponto de partida uma análise ética e prática do cuidado de longo prazo, por considerar que a autonomia é um ideal cultural significativo. A autonomia está relacionada à independência, o que se contrapõe ao cuidado de longo prazo, pois a pessoa que depende desse tipo de cuidado sente-se vulnerável a essa condição de dependência, "vê-se como um fardo, como uma pessoa menos completa" (AGICH, 2008, P. 40).

Se refletirmos sobre nossa condição humana, daremos conta do quanto somos vulneráveis, dado que estamos frequentemente expostos a vários tipos de perigos: perigo de adoecer, ser agredido, fracassar, morrer. Viver humanamente significa, portanto, viver na vulnerabilidade (ROSELLó, 2009). Como diria um personagem de Guimarães Rosa (2001, P. 33), em frase antológica do livro 'Grande Sertão Veredas': "viver é muito perigoso".

Para Butler (2006), a vulnerabilidade é condição própria de nosso estar no mundo, é uma vulnerabilidade original em relação ao outro. Para Roselló (2009), a vulnerabilidade significa fragilidade, precariedade e a experimentamos pessoal e coletivamente.

Uma possibilidade de organização de serviço de saúde que colabora para preservar a autonomia da pessoa dependente de cuidado de longo prazo e vivencia de perto a vulnerabilidade humana é a atenção domiciliar.

No Brasil, a atenção domiciliar integra, desde agosto de 2011, a Rede de Urgência e Emergência (RUE) sob o título 'Programa Melhor em Casa' e, atualmente, é regulamentado pela Portaria GM/MS no 825 de 25 de Abril de 2016. No referido programa, a atenção domiciliar é considerada uma 
modalidade de atenção à saúde integrada às Redes de Atenção à Saúde (RAS), com ações de prevenção, tratamento de doenças, reabilitação, paliação e promoção à saúde, prestadas em domicílio. (BRASIL, 2016, P. 33).

É desenvolvido por meio do Serviço de Atenção Domiciliar (SAD) e composto por Equipes Multidisciplinares de Atenção Domiciliar (Emad) e Equipes Multidisciplinares de Apoio (Emap). O programa entende como

cuidador pessoa(s), com ou sem vínculo familiar com o usuário, apta(s) para auxiliá-lo em suas necessidades e atividades da vida cotidiana e dependendo da condição funcional e clínica do usuário, deverá(ão) estar presente(s) no atendimento domiciliar. (BRASIL, 2016, P. 33).

Como critérios de admissão no SAD, a pessoa doente deve estar acamada, necessitar de assistência, no mínimo, uma vez por semana e ter um cuidador responsável diuturnamente.

O Programa Melhor em Casa organiza a assistência domiciliar em três níveis: Atenção Domiciliar tipo 1 (AD1) para pacientes crônicos de baixa complexidade, que deveriam ser seguidos uma vez ao mês por profissionais das unidades básicas da Rede de Atenção Básica (RAB); AD2 para pacientes de média complexidade, necessitando acompanhamento semanal do SAD; e AD3 para pacientes com maior complexidade e necessidades, recebendo assistência do SAD com maior frequência (BRASIL, 2016).

As visitas domiciliares realizadas pelo SAD pretendem avaliar o grau de dependência do paciente e a capacidade do cuidador para o cuidado necessário, condições preliminares para a admissão no programa, bem como têm como atribuição acompanhar a pessoa dependente de cuidados de longo prazo até alcançar a alta do programa por cura, por internação hospitalar ou por morte.
Os profissionais dos serviços de atenção domiciliar encontram, com certa frequência, pessoas em situação de vulnerabilidade, que, muitas vezes, não têm consciência de que estão sendo negligenciadas ou violentadas por outros. São pessoas, na maioria idosas, vivendo realidades que demandam ações de intervenção do serviço social e, por vezes, ação da justiça para proteger seus direitos humanos fundamentais.

Para atender às necessidades advindas principalmente da população idosa, em países desenvolvidos, vê-se, além dos serviços de saúde domiciliares (HOMECARE), a existência de serviços de apoio sociais no domicílio, os quais oferecem uma gama de serviços tais como fornecimento de refeições, realização de limpeza, serviço de compras delivery, auxílio para banho; respite care, i.e., cuidador para cobrir o período de folga do cuidador principal; serviço de enfermagem; monitoramento à distância; dentre outros (GENET, 2011).

Outra inovação em serviços domiciliares e que envolve a saúde e o serviço social foi feita no Japão e se baseia em um sistema de banco de horas no qual pessoas voluntárias ganham 'créditos de tempo' para cuidar de pessoas idosas em sua comunidade. Os voluntários podem usar os créditos para comprar serviços similares para eles mesmos, mais tarde na vida ou no presente, para seus parentes idosos e frágeis que moram em outra cidade distante, ou, ainda, para outras pessoas que precisam (HAYASHI, 2011).

Nesta pesquisa, o objetivo foi o de compreender o processo de cuidado desenvolvido por um SAD de um município de médio porte do estado de São Paulo em que se verificaram as relações do SAD com os demais serviços da RAS. Mais especificamente, analisaram-se as relações entre os serviços que compõem a RUE com os hospitais, Unidades de Pronto Atendimento (UPA), Pronto Socorros e a RAB.

$\mathrm{E}$, além das questões de organização e planejamento da assistência domiciliar no âmbito do Sistema Único de Saúde (SUS), 
ressaltou-se, na pesquisa, o encontro com os doentes, usuários do SAD, bem como a experiência do cuidar assumido por familiares-cuidadores.

Assim, o objetivo deste artigo é evidenciar experiências do cuidar e ser cuidado e apresentar a visão de cuidadores familiares sobre um SAD.

\section{Percurso metodológico}

Esta pesquisa é um estudo de caso de um SAD de município de médio porte no estado de São Paulo, com população estimada para 2015 de 233.249 habitantes e área territorial de 1.136.907 $\mathrm{km}^{2}$ (SEADE, 2017). Omitiu-se o nome do município para preservar a identidade dos profissionais envolvidos na pesquisa e adotou-se a letra 'N' como referência ao município.

O serviço de assistência domiciliar no município N iniciou suas atividades em 1997 como Programa de Internação Domiciliar (PID). Em meados de 2002, passou a ser chamado de Programa de Atendimento Domiciliar (PAD) sendo, em final de 2012, habilitado como SAD do 'Programa Melhor em Casa', com duas Emad e uma Emap habilitadas, que dividem o território municipal em duas grandes regiões.

Neste estudo qualitativo, adotou-se um 'ethos cartográfico' em todo o caminho da pesquisa. Na cartografia, os dados são produzidos a partir da observação das ações do cotidiano, do acompanhamento de processos de trabalho e das relações interpessoais que estão envolvidas na produção do cuidado. Esse relacionamento entre o pesquisador ou o cartógrafo e os sujeitos do estudo produz, segundo Melucci (2005, P. 329), "modificações no campo", que são intervenções que "provocam transformações cognitivas devidas à circulação das ideias que ela introduz".

Este artigo relata cenas registradas durante visitas domiciliares realizadas pelos profissionais do SAD e transcrições de gravações das entrevistas com cinco cuidadoras de pacientes assistidos pelo serviço.
O trabalho de campo ocorreu no período de 15.1.2015 a 6.8.2015, uma vez por semana, oito horas por dia, e as cenas vivenciadas no campo foram registradas em diários de campo em forma de narrativas, resultando no material empírico do estudo.

Para seleção das cuidadoras a serem entrevistadas, adotaram-se as planilhas que consolidam as informações de todos os pacientes atendidos pelo $\mathrm{SAD}$, nas quais constam os nomes dos pacientes e cuidadores, endereços e telefones para contato. Selecionaram-se cuidadores de dez pacientes com diferentes patologias e graus de dependência e admitidos no SAD por períodos que variavam entre um mês e cinco anos. Após contato telefônico com os cuidadores desses pacientes, cinco cuidadoras aceitaram conceder uma entrevista, as quais foram agendadas em dias e horários distintos.

As entrevistas com as cuidadoras foram realizadas com a intenção de conhecer a visão sobre o $\mathrm{SAD}$ e suas vivências. Nessas entrevistas, valorizaram-se as experiências de vida narradas pelas cuidadoras no processo do cuidado, tomando como referência três diretrizes:

A entrevista visa não à fala 'sobre' a experiência e sim a experiência 'na' fala; a entrevista intervém na abertura à experiência do processo do dizer; a entrevista busca a pluralidade de vozes. (TEDESCO; SADE; CALIMAN, 2013, P. 304).

Solicitou-se a cada cuidadora que falasse sobre como havia conhecido o SAD; o tempo de espera para receber a primeira visita em casa; a frequência das visitas; a avaliação sobre o SAD; além de sugestões para melhora do atendimento. Também, considerou-se importante conhecer se as cuidadoras têm algum tempo livre para descanso e lazer e quais os impactos da atividade em suas vidas.

Ao final das entrevistas, a experiência de cada cuidadora iluminava aspectos sobre a atenção domiciliar considerados muito importantes para complementar e 
enriquecer as observações no acompanhamento das equipes.

Como estratégia de análise dos dados, a primeira aproximação foi a definição de Planos de Corte, para uma primeira sistematização do material empírico. Nesse sentido, realizou-se leitura extensiva das cenas registradas e das transcrições das gravações das entrevistas.

À medida que se efetuava a leitura dos diários de campo e da transcrição das entrevistas, ia-se definindo certos Planos de Corte, que correspondiam, em boa medida, aos aspectos presentes nas recomendações e diretrizes da Política de Atenção Domiciliar, tendo como balizador os objetivos propostos na pesquisa.

Dessas opções, resultaram quatro Planos de Corte: (i) A moldura da gestão municipal e os limites da gerência; (ii) A produção da equipe; (iii) $\mathrm{O}$ binômio paciente-cuidador; e (iv) O SAD nas redes de atenção.

Esse movimento de leitura, inúmeras vezes efetuado, que recortava cenas e falas dos entrevistados e as colocavam em 'caixas' do tipo pastas-arquivo, organizadas no processador de texto Word ${ }^{\circledR}$, corresponderam aos Planos de Corte, resultando na primeira aproximação analítica do empírico. Dos Planos de Corte apresentados neste artigo, interessa aprofundar o 'binômio paciente-cuidador'.

Na segunda aproximação analítica, evidenciaram-se Planos de Visibilidade mais expressivos dentro dos Planos de Corte.

Os Planos de Visibilidade resultam da análise de cenas registradas que guardam alguma relação entre si, e que, quando conectadas, vão revelando elementos importantes do cotidiano do trabalho da equipe nem sempre visíveis quando 'olhados de fora'. Os 'Planos' vão adquirindo visibilidade a partir de 'conexões de cenas' que mostram as relações inter-humanas e suas intensidades, que, ao final, resultam no cuidado em saúde ou nas relações internas à equipe ou à família.

Para o Plano de Corte 'O binômio paciente-cuidador', identificaram-se os Planos de Visibilidade: (i) 'O universo da perda da autonomia: o acamado', apresentando o encontro com a vulnerabilidade humana e a realidade da perda da autonomia das pessoas acamadas; (ii) 'O universo do cuidador', no qual se vê a experiência das pessoas que cuidam de outras; e (iii) 'O ponto de vista do cuidador', que apresenta a voz dos cuidadores dos pacientes usuários do SAD, possibilitando conhecer o que pensam desse serviço e da rede de serviços de saúde, bem como o impacto do ato de cuidar em suas vidas.

Esta pesquisa foi aprovada pelo Comitê de Ética em Pesquisa da Universidade Federal de São Paulo (Unifesp), sob número do CAAE 39179014.0.0000.5505 e parecer $\mathrm{n}^{\mathrm{o}}$ 907.048 de 16/12/2014, atendendo às exigências da Resolução no 466/12 do Conselho Nacional de Saúde. Os participantes da pesquisa, ao serem convidados, receberam uma primeira explicação sobre os procedimentos da pesquisa e, em seguida, procederam à leitura do Termo de Consentimento Livre e Esclarecido (TCLE). Após a concordância em participar, assinaram duas vias do Termo, permanecendo a primeira via com a pesquisadora e a segunda via com o participante.

Ressalta-se que os nomes usados na descrição das cenas para as cuidadoras e pacientes são fictícios para que se preserve sua identidade.

\section{Resultados e discussão}

No Plano de Visibilidade (i) 'O universo da perda de autonomia: o acamado', diferentes realidades sociais e humanas estão presentes enfrentando o mesmo problema - a doença, que exige cuidado de longo prazo. As cenas registradas revelam o encontro da equipe do SAD com a vulnerabilidade humana em algumas situações-limite vivenciadas por pessoas, na maioria idosas, dependentes de cuidados de longo prazo acarretados por doenças crônicas e degenerativas.

As cenas escolhidas para compor esse Plano de Visibilidade são exemplos de vários tipos de vulnerabilidades percebidas nos 
diversos contextos de enfermidade.

No caso relatado a seguir, a paciente tem permanecido sozinha em sua casa, mesmo precisando de ajuda para fazer um curativo, dentre outras demandas. O SAD a admitiu porque uma sobrinha referiu ser sua cuidadora e a intenção era encontrar essa 'cuidadora' para conscientizá-la de que a paciente não pode permanecer sozinha, além de levantar possibilidades para resolução dessa situação.

Fomos à casa de D. Rita, 84 anos; mora sozinha e tem úlcera varicosa no membro inferior direito, que limita seus movimentos por permanecer com a perna enfaixada. A ferida é extensa e com secreção purulenta. A auxiliar de enfermagem (D) e a Enfa. (H) fazem o curativo. A senhora Rita está repetitiva na conversa e esquecida dos momentos atuais. Na casa tem um senhor que está cortando o mato no quintal; ele é um vizinho. A sobrinha não compareceu ao encontro marcado previamente pela assistente social ( $R$ ). Surge, passando em frente à casa, uma senhora conhecida de D. Rita, que entra na casa e, após entender quem somos, fornece um número de telefone para $(R)$, que é de uma outra sobrinha de D. Rita. (R) tentou contato por celular com essa sobrinha, que desligou o telefone no meio do assunto. $(R)$ conversa com D. Rita com calma, tentando explicar que ela não pode ficar sozinha em casa e precisa de alguém para fazer curativo e cuidar dela. Durante a conversa, fica sabendo que D. Rita 'ajuda' com dinheiro à sobrinha inscrita como cuidadora. A equipe vai conhecer as condições de vida da paciente e constata que, na cozinha, só há arroz, feijão e farinha de miIho para comer; há muitas batatas podres numa fruteira e a geladeira está vazia. No tanque, havia várias faixas-crepe para lavar e roupas sujas. Aquela conhecida que havia entrado para falar conosco se comprometeu a fazer o almoço naquela manhã para D. Rita e ver se, na Pastoral da Saúde, alguém poderia vir diariamente trocar o curativo. Despedimo-nos. [A cena foi registrada em 15.1.2015].

Na situação vivenciada, há clara negli- gência de cuidados, solidão e exploração financeira, ou seja, vulnerabilidades de ordem ética, social e cultural.

A vulnerabilidade ética, do ponto de vista filosófico, refere-se ao dever moral de proteger o sujeito mais frágil e depreciável. $\mathrm{Na}$ concepção de Lévinas citado por Roselló (2009, P. 63), "sofrer por outro é tê-lo ao cuidado, apoiá-lo, estar em seu lugar, consumir-se por ele". A vulnerabilidade social se apresenta pelo isolamento, desproteção; no caso, a idosa também era explorada economicamente. A vulnerabilidade cultural refere-se à ignorância e ao desconhecimento sobre um determinado saber, no caso, a doença, suas implicações e cuidados.

Uma possibilidade de resposta para melhor acompanhamento da população vulnerável é o modelo da Estratégia Saúde da Família (ESF), que aumenta a cobertura nos municípios brasileiros, pois essas unidades de saúde estão mais próximas da população devido ao seu modelo de atenção (BRASIL, 2017). Outra possibilidade que colabora na diminuição das vulnerabilidades é a conscientização social quanto ao Estatuto do Idoso, publicado na forma da Lei $\mathrm{n}^{\circ} 10.741$ de 1.10.2003, que regula os direitos das pessoas com idade a partir de 60 anos (BRASIL, 2003). É uma legislação protetora, que avançou em aplicação desde sua publicação, embora ainda esteja longe de ser efetiva, porque precisa de maior divulgação na sociedade e maior mobilização social para forçar mudanças necessárias e investimentos em projetos sociais de transformação.

Na próxima cena, presencia-se um 'grito de socorro' com um pedido de assistência de enfermagem diuturno no domicílio.

Chegamos à casa de Carlos, portador de Esclerose Lateral Amiotrófica (ELA), para uma avaliação socioeconômica. Trata-se de processo que tramitou no Ministério Público e resultou em liminar favorável à família, determinando à Secretaria Municipal de Saúde o fornecimento de assistência de enfermagem no domicílio diuturnamente. 
A Assistente Social do SAD foi fazer uma avaliação social determinada pela assessoria jurídica da Secretaria de Saúde.

A ação foi solicitada pela esposa e cuidadora que alega não ter mais condições físicas e psicológicas de cuidar de Carlos, pois são oito anos de dedicação.

Carlos é um homem jovem, em torno de 45 anos, está deitado em uma cama hospitalar em um quarto escuro, pois não queria luz. Está emagrecido e com sinais de paralização dos membros inferiores. A casa, herança dos pais, é simples e ao lado funciona um salão de cabeleireiro, onde sua irmã trabalha. Até uma semana antes da visita, o paciente estava morando em seu apartamento, mas, devido à dificuldade de transportá-lo ao banheiro, a família resolveu montar um quarto na casa dos pais, por ter mais espaço e a porta do banheiro ser mais larga, permitindo que uma cadeira de banho passe por ela.

Percebe-se muito sofrimento, muitas privações provocadas pela doença do paciente; a esposa está visivelmente desgastada e deprimida. À medida que respondia ao questionário social, percebíamos que era mesmo a única saída que essa mulher poderia enxergar, principalmente por viver sob um rígido controle econômico, contando apenas com uma pensão e a ajuda da filha adolescente, que trabalha de dia e estuda à noite. Ainda assim, pagam um plano da Unimed para garantir a fisioterapia de Carlos duas vezes por semana. O restante, ela recorre ao SUS na UBS, onde pega fraldas e medicamentos.

A assistente social ( $R$ ), após escutar as demandas e motivos da cuidadora, explicou que a determinação da liminar talvez demore para ser cumprida pela falta de funcionários na prefeitura, mas não descartou a possibilidade de o Estado enviar algum funcionário para fazer cumprir a determinação judicial. Despedimo-nos e ficamos desoladas com a situação. [A cena foi registrada em 15.1.2015].
Como em tantos outros casos, a falta de apoio do setor saúde sobrecarrega a família em relação ao cuidado. Muitos processos judiciais ocorrem devido ao desespero familiar com a falta de efetivo apoio aos cuidadores, pois não há serviços de apoio social domiciliar, como os identificados por Genet (2011).

A possibilidade de outras formas de atenção domiciliar, com cuidadores mantidos por impostos ou com participação voluntária, é uma experiência que tem sido usada em vários países desenvolvidos, como Japão e Inglaterra (HAYASHI, 2011).

Aqui também surge a questão dos arranjos organizados pela população para conseguir o atendimento às necessidades de saúde, como uso do sistema de saúde complementar para fisioterapia e médico da Unidade Básica de Saúde (UBS) para outras demandas, configurando os 'mapas de cuidado' de Cecílio, Carapinheiro e Andreazza (2014).

Durante aquela visita, a cuidadora descreveu o comportamento de irritação e sofrimento do paciente com a situação de doença, provocando uma sensação de impotência. Pergunta-se o que passa na cabeça de uma pessoa que há oito anos está enfrentando a evolução de uma doença crônica.

A tomada de consciência do 'estar doente', segundo Caretta e Petrini (1998), vai acontecendo de acordo com as limitações que surgem durante o processo de doença, e essa conscientização é dolorosa, não só fisicamente, pela perda de capacidades funcionais, pois é acompanhada por uma dor complexa e profunda que surge pela consciência crescente de sua condição, como magistralmente descrito por León Tosltói em uma de suas novelas mais conhecidas, 'A morte de Ivan Ilitch', escrita em 1886, e que foi analisada por Cecílio (2009).

É a dor de uma pessoa que, de certo ponto da vida, deve suspender suas expectativas no futuro e enfrentar a realidade do sofrimento, que é carregada pelo medo da doença e sua evolução, medo pelo futuro da família, preocupação com o peso econômico para a 
família, enfim, são muitos sofrimentos que precisam ser trabalhados interiormente pelo doente. Cada pessoa, então, dá um significado para a sua doença (CARETTA; PETRINI, 1998).

Diante dos significados que a pessoa doente adota para a doença, ela usa determinados comportamentos como mecanismos de defesa para enfrentá-la. Segundo Caretta e Petrini (1998), podem ser comportamentos de negação da doença; dissimulação; divisão, quando ora concorda com o fato, ora discorda; projeção, que atribui a doença a outras coisas, como remédios etc.; regressão, que infantiliza; complacência, que faz tornar-se vítima; submissão, que faz tornar-se extremamente obediente às condutas médicas; racionalização, que permite se adaptar à realidade; e depressão. Esses comportamentos podem se atenuar diante da melhora do quadro da doença até desaparecer, quando há a cura.

Além disso, para as pessoas que estão próximas da morte, o estado emocional pode variar progressivamente, alternando entre o medo e a esperança, estados de negação da doença, raiva, negociação com os médicos ou familiares, depressão e aceitação (CARETTA; PETRINI, 1998).

$\mathrm{Na}$ cena seguinte, depara-se com outro modo de encarar o sofrimento da dependência total:

Chegamos noutra casa, um local bem desgastado e sujo. Quem nos atende ao portão é Ivo, que, depois, entendi que é o marido e cuidador da paciente Luíza. Entramos numa casa escura e muito desorganizada. Subimos uma escada estreita e chegamos a um quarto isolado. Lá encontramos Luiza, 42 anos, deitada em uma cama hospitalar, muito emagrecida, com sonda nasoenteral para alimentação, com os olhos semiabertos e dispneica, com um pouco de secreção pulmonar. Ivo conta que foi à Santa Casa e o médico disse que talvez Luíza precise de traqueostomia, mas o cuidador demonstra seu conhecimento sobre a técnica e sabe que o caso de Luiza é irreversível e ele quer evitar. Também fala para o Dr. (K) sobre a gastrostomia que deverá ser feita na Santa
Casa e que está aguardando o agendamento pela equipe. Ele está animado, porque sabe que esse recurso pode melhorar a condição de nutrição de Luíza. Ivo conta que está limpando os olhos de Luíza, que agora não enxerga, mas acha que ela ainda vê vultos. Conforme ele vai contando vai falando com ela também: - Não é Luíza?! Conta que o refluxo gástrico melhorou com o uso de Domperidona, que usou aumentando a dose, também, para resolver a distensão abdominal e constipação intestinal. Diz: - Ela evacuou um monte, que eu até fiquei feliz! [Risos]. [...]. Pergunto há quanto tempo Luíza adoeceu e ele responde: - Faz nove anos que ela começou com umas dores no joelho, foi ao ortopedista, fez exames, não deu nada. Depois foi piorando, foi ao neurologista, fez tomografia e daí para frente começou a ter a mobilidade comprometida e há três anos está acamada. Conta ainda que a doença está presente na família dela. [...] Ao sairmos do quarto e descermos a escada, encontramos uma das filhas, a mais velha; estava na cozinha lavando louça. Uma jovem bonita que lembrava muito a mãe. Pensei que Luíza deveria ter sido uma jovem muito bela antes de adoecer. [A cena foi registrada em 6.4.2015].

Quando se conheceu essa família, impressionou a forma como o marido cuidador se relacionava com sua esposa. O cuidador se comunicava todo o tempo com a paciente, afásica, fazendo a ligação com o médico e a equipe de enfermagem com uma alegria que era contagiante.

Na situação narrada, o relacionamento entre o marido cuidador e a esposa doente e completamente dependente, revelava a existência de uma autonomia preservada em sua dignidade e integridade humana, princípios que fazem parte também da autonomia, conforme Agich (2008, P. 32, GRIFO NOSSO): A autonomia é considerada equivalente à
liberdade, seja ela positiva ou negativa, no
sentido de Isaiah Berlin (1969, P. 118-172), ao au-
togoverno, à autodeterminação, à liberdade
da vontade, 'à dignidade, à integridade', à da vontade, 'à dignidade, à integridade', à 
individualidade, à independência, à responsabilidade e ao autoconhecimento [...].

De fato, a doença, considerando o senso comum, retira a liberdade da pessoa, retira sua autonomia, limita suas realizações e, sobretudo, quando há dor, leva à percepção da fragilidade implícita no ser humano. Essa vivência nos amedronta naturalmente com a evolução do envelhecimento, mas está presente em todo o curso da vida.

Nesse sentido, vendo a experiência de Ivo e Luíza, observa-se que o processo da doença é enfrentado de forma mais leve quando a pessoa doente se sente acompanhada e considerada por um cuidador que expressa carinho, respeito e proximidade, atitudes tanto do cuidador como do doente quando aceitam o sofrimento e enfrentam a dor com um sentido. E essa postura pode lhes dar maior liberdade interior.

Segundo Viktor Frankl (1999, P. 76):

Em última análise, viver não significa outra coisa que arcar com a responsabilidade de responder adequadamente às perguntas da vida, pelo cumprimento das tarefas colocadas pela vida a cada indivíduo, pelo cumprimento da exigência do momento.

Compartilha-se a visão de Frankl (1999), porque ela é bastante concreta; a exigência do momento a que ele se refere vem acompanhada de um sentido da existência que é singular para cada pessoa. Assim, nenhum destino pode ser comparado com outro, não se repete, porque a cada experiência se deve dar uma resposta.

Continua-se com o pensamento de Frankl (1999, P. 77) para entrar na dinâmica do sentido do sofrimento, que, às vezes, não faz sentido para quem está de fora.

Quando um homem descobre que seu destino Ihe reservou um sofrimento, tem que ver neste sofrimento também uma tarefa sua, única e original. Mesmo diante do sofrimento, a pessoa precisa conquistar a consciência de que ela é única e exclusiva em todo o cosmo dentro deste destino sofrido. Ninguém pode assumir dela o destino e, ninguém pode substituir a pessoa no sofrimento. Mas na maneira como ela própria suporta este sofrimento está também a possibilidade de uma realização única e singular.

Mesmo com essa proposição diante da vida, é muito importante que haja um apoio social que dê o suporte necessário para o enfrentamento dos momentos mais difíceis.

No Plano de Visibilidade (ii) 'O universo do Cuidador', viu-se que, na maioria das famílias, o cuidado é assumido por uma mulher - filha, esposa, mãe, irmã, sobrinha -, muitas vezes, sozinhas nessa atividade, gerando mudanças em vários aspectos da vida. Nesta pesquisa, $83 \%$ dos cuidadores são mulheres.

Fomos à casa de uma senhora idosa, D. Maria, 80 anos, teve um AVC há oito anos e tem sérias sequelas. É cuidada por um de seus nove filhos, solteiro, em torno de 45 anos e não trabalha para cuidar da mãe. Preocupado com um prurido que surgiu no quadril de sua mãe, pede à Enfa. $(H)$ que olhe o local, $(H)$ que resolve pedir uma avaliação do médico da manhã. Pergunto ao cuidador se alguém o ajuda na rotina e ele responde conformado que suas irmãs trabalham; por isso, não tem ajuda. Após a visita, já no carro, a auxiliar (D) comenta: - 'É! Uma mãe cuida de dez filhos, mas dez filhos não cuidam de uma mãe!' - fala indignada com a situação de o cuidador fazer sozinho o cuidado. [A cena foi registrada em 15.1.2015].

\section{$[\ldots]$}

No grupo de cuidadores, ao final, aproximei-me de um senhor idoso e iniciei conversa. Era o Sr. Raul, cerca de 75 anos, cuidador de sua ex esposa. Contou que os filhos não querem cuidar da mãe; no máximo levam-na de carro ao médico. Ele acha que os filhos agem assim porque ela sempre foi muito autoritária. Procurei ouvi-lo. 
Contou sobre sua rotina, que dorme pouco à noite, porque sua ex esposa acorda muitas vezes. Ela foi fumante a vida toda e agora depende de oxigênio, dorme sentada e tosse muito. Ele levanta às 5 horas porque ela fica chamando para ajudá-la no banho e depois de dar o café da manhã, ele consegue cochilar um pouco [...]. [A cena foi registrada em 29.1.2015].

Nos dois casos narrados acima, o cuidado é realizado por homens, o que não é comum. Assim como outros cuidadores, eles enfrentam certo isolamento ou solidão em relação às tarefas do cuidado e parecem conformados com a situação, como se fosse uma missão a ser cumprida.

Outro aspecto identificado em uma das cenas é a realidade que muitas pessoas idosas estão sob o cuidado de outras pessoas idosas, como visto em várias outras cenas. Assim como em vários outros países desenvolvidos, nossa população está envelhecendo rapidamente.

Nesse sentido, cita-se o exemplo do Japão, que, por ter uma grande população idosa, deparou-se com o problema do cuidado de longo prazo. A cobertura dos serviços de saúde era feita pelo sistema de seguro-saúde, mas não atendia a todas as demandas das famílias cuidadoras. Assim, inovaram com um sistema de socialização do cuidado, criando uma rede de ajuda mútua para suplementar o LTCI (Long Term Care Insurance) (HAYASHI, 2011).

Entende-se que a realidade exigirá a tomada de novos caminhos, com a adoção de modelos de serviços de apoio social inovadores que servirão às diversas concepções de atenção domiciliar.

Segue-se com mais uma experiência:

É! Às vezes, o nosso limite não é tanto físico, mas psicológico, de estar ali e não poder fazer nada. De ouvir o gemido, o grito e não poder ajudar! Às vezes, a única coisa que podemos fazer é mandar uma mensagem lá pra cima, só Deus! [...]

A gente está andando, mexendo, pegando as coisas! Ele não! Está parado, sem se mexer! Esse é o meu maior sofrimento! [...]. [A cena foi registrada em 2.4.2015].

Na narrativa acima, a cuidadora levanta dois aspectos. O primeiro é a experiência inexplicável do sofrimento, que alterou o itinerário da vida pessoal e familiar, que a faz reconhecer a vulnerabilidade do marido doente e dar um sentido metafísico ao sofrimento, ou seja, busca na fé em Deus a força para se sustentar e sustentar o seu doente.

O segundo aspecto envolve a alteridade, a dimensão interpessoal, que coloca o centro da vida não no $\mathrm{Eu}$, mas no Tu. Assim, as ações, os pensamentos estão fora da pessoa, que vive a abertura radical ao outro. Indica que "cuidar de alguém é, portanto, não somente estar fisicamente com alguém, mas ser-com-ele, no sentido mais existencial do termo" (ROSELLó, 2009, P. 136).

A vivência da alteridade como 'ethos' do cuidar faz parte de um cuidado ideal a todo ser humano e é a atitude esperada de um cuidador, dos profissionais da saúde e da comunidade justamente porque está implícito um cuidar singular, único.

Mas, ao se vivenciar esse encontro com a cuidadora, também se nota em sua fala a sua solidão no processo de cuidar, bem como nas cenas narradas do encontro com outros cuidadores.

Novamente, aparece esse sentimento de isolamento, sensação de estar só na luta diária e, justamente por isso, a colaboração efetiva e real entre as pessoas da comunidade, como voluntários, profissionais da saúde, familiares é fundamental nesse processo do cuidar.

Finaliza-se com o Plano de Visibilidade (iii) - 'O ponto de vista do cuidador', no qual emerge a voz dos cuidadores dos pacientes usuários do SAD por meio das entrevistas, possibilitando conhecer o que pensam do serviço e da rede de serviços de saúde, como também do impacto do ato de cuidar em suas vidas.

Quanto ao tempo de espera para o atendimento no domicílio, as cuidadoras relataram: 
Não demorou nada, acho que nem uma semana! Não demorou nada, nada, eles já foram! Foram uma médica e três enfermeiras! [Transcrição de entrevista com a cuidadora Gina em 23.6.2015].

\section{$[\ldots]$}

Porque ela [a paciente] tem o médico que atende [particular], mas para chamar em casa é caro! Aí eu fui lá numa quarta, e na sexta feira já vieram! [...] eles vieram duas vezes com o médico e depois de mais de um mês que veio a fisioterapeuta. [Transcrição de entrevista com a cuidadora Rosa em 9.10.2015].

Nos relatos sobre o tempo de espera entre a solicitação e a primeira visita do SAD, é visível que as equipes procuraram viabilizar os atendimentos com celeridade. Ressalta-se a divisão das equipes entre os diferentes profissionais, sendo mais frequente a atuação da equipe de enfermagem com o médico ou a atuação isolada da equipe de enfermagem, assim como as fisioterapeutas, que frequentemente atuam em uma visita secundária. De certa maneira, esse modo de operar indica não um trabalho em equipe, mas um trabalho por especialidade, podendo acarretar em resposta inadequada às necessidades de saúde da população alvo.

Outra questão surgida em uma das falas se relaciona à composição de 'mapas de cuidado', conforme evidenciado por Cecílio, Carapinheiro e Andreazza (2014), quando há a constatação que a visita de um médico particular é economicamente inviável e a maneira de resolver o problema é acionando o SAD, que é um serviço do SUS.

Em relação à qualidade da assistência, as cuidadoras têm opiniões diversas:

Rosa: Olha! Eu vou te falar da equipe, do médico, das enfermeiras; achei excelente o atendimento. Mas da fisioterapeuta eu não sei. Ah! eu achei meio fraca, não sei porque demorou muito para vir! Ah! Ela estava afastada! [...] mas se eu tivesse ficado esperando, se eu não tivesse a iniciativa de pagar [fisioterapeuta], talvez minha mãe não estivesse andando ainda! Não é? Porque essa outra que eu paguei, ela vinha com a bola, sabe, e a da Prefeitura não! Era bem assim! Bem fraquinha! [...] O médico e as enfermeiras uma graça! Isso foi 10! [...]. [Transcrição de entrevista com a cuidadora Rosa em 9.10.2015].

Na narrativa, há fortes críticas em relação ao serviço de fisioterapia e valorização da atuação das equipes de enfermagem e médica. Parece que a qualidade é avaliada observando-se o empenho técnico, o relacionamento interpessoal, o uso de materiais apropriados e o fornecimento de materiais de consumo, pontos que influenciam as condições de cuidado, evolução clínica do paciente e estabelecimento de vínculos.

Os gastos com materiais, dietas e medicamentos são altos, um peso no orçamento familiar, tornando imperativa a procura por recursos oferecidos pelo sistema de saúde de forma gratuita, além da necessidade de criatividade e das informações de vários profissionais para suprimento das demandas geradas durante o processo de doença.

Sobre a possibilidade de descanso ou de lazer para promoção da saúde física e mental, as cuidadoras ressaltaram suas dificuldades para sair de casa e ter um tempo para 'respirar'.

\section{Considerações finais}

$\mathrm{Na}$ investigação, emergiu com muita força a vivência da vulnerabilidade humana em diferentes perspectivas e o sentido que cada família dá ao sofrimento vivido pelo familiar dependente de cuidado de longo prazo.

Tornou-se evidente a solidão do cuidador no cuidado, ressaltando a necessidade de se pensar em outros serviços de apoio ao cuidador, com diferentes arranjos sociais, bem como o valor que tem o grupo de cuidadores como espaço de intervenção e acompanhamento da saúde física e mental do cuidador. 
Foi possível 'ouvir' o que os cuidadores pensam do SAD, trazendo seus elogios e críticas, ressaltando a necessidade de a equipe multiprofissional realizar maior número de visitas durante o mês ao mesmo paciente; trabalhar de forma integrada, principalmente em visitas de avaliação; construir um plano individualizado de cuidados e melhorar a formação dos profissionais de saúde que trabalham nesse espaço de cuidado, que é o domicílio.

A percepção que o leigo cuidador tem da inabilidade ou insuficiência do profissional o impulsiona a procurar outros profissionais que possam resolver as necessidades de saúde identificadas, o que confirma que as pessoas compõem seus mapas de cuidado com serviços públicos e privados usando a criatividade para resolver as falhas do sistema de saúde.

Encontraram-se pessoas que, ao negligenciar o cuidado, não poderiam assumir o papel de cuidadores, principalmente idosos cuidando de idosos, incorrendo em problemas éticos, humanos e sociais a serem administrados pelo SAD. Nesses encontros com os cuidadores, presenciou-se a atuação dinâmica e atenciosa das equipes do SAD, permeadas pelo diálogo e orientações aos cuidadores e pacientes.

Do encontro com os cuidadores, persistiram as inquietações para diminuir sua carga de trabalho e a solidão no trabalho de cuidar.

É preciso avançar na atenção domiciliar por meio da criação de serviços de apoio social voltados a atender principalmente a população idosa com algum grau de dependência por doença crônica, de forma a colaborar para manutenção da autonomia dessas pessoas portadoras de dependência, bem como da saúde do cuidador.

\section{Colaboradores}

Os autores contribuíram igualmente para a concepção, planejamento, análise e interpretação dos dados, assim como para a elaboração e a aprovação da versão final deste manuscrito. 


\section{Referências}

AGICH, G. J. Dependência e autonomia na velhice: um modelo ético para o cuidado de longo prazo. São Paulo: Loyola; Centro Universitário São Camilo, 2008.

BRASIL. Lei no 10.741 de 1 de outubro de 2003. Diário Oficial [da] República Federativa do Brasil. Brasília, DF, 1 out. 2003. Disponível em: <http://presrepublica. jusbrasil.com.br/legislacao/98301/estatuto-do-idoso-lei-10741-03>. Acesso em: 31 out. 2016.

Ministério da Saúde. Portaria GM/MS no 825 de 25 de abril de 2016. Redefine a Atenção Domiciliar no âmbito do Sistema Único de Saúde (SUS) e atualiza as equipes habilitadas. Diário Oficial [da] República Federativa do Brasil. Brasília, DF, 25 abr. 2016. Disponível em: <http://www.brasilsus.com.br/images/ portarias/abril2016/dia26/portaria825.pdf $>$. Acesso em: 31 out. 2016.

Ministério da Saúde. Portaria n ${ }^{\circ}$ 2.436, de 21 de setembro de 2017. Diário Oficial [da] República Federativa do Brasil. Brasília, DF, 21 set. 2017. Disponível em: <http://pesquisa.in.gov.br/impren$\mathrm{sa} /$ jsp/visualiza/index.jsp?jornal=1\&pagina $=68 \& \mathrm{da}$ ta=22/09/2017>. Acesso em: 18 out. 2017.

BUTLER, J. Vida precária: el poder del duelo y la violência. 2. ed. Buenos Aires: Paidós, 2006.

CARETTA, F.; PETRINI, M. Accanto al malato: lineamenti di assistenza sanitária e pastorale. 4. ed. Roma: Città Nuova Editrice, 1998.

CECÍLIO, L. C. O. A morte de Ivan Ilitch, de Leon Tolstói: elementos para se pensar as múltiplas dimensões da gestão do cuidado. Interface, Botucatu, v. 13, supl. I, p. 545-555, 2009. Disponível em: <http://www. scielo.br/pdf/icse/v13sl/a07vl3sl.pdf>. Acesso em: 9 ago. 2017.

CECÍLIO, L. C. O.; CARAPINHEIRO, G.; ANDREAZZA, R. (Org.). et al. O agir leigo e o cuidado em saúde: a produção de mapas de cuidado. São Paulo: Hucitec; Fapesp, 2014.
CRUZ, D. C. M. et al. As vivências do cuidador informal do idoso dependente. Revista de Enfermagem Referência, Coimbra, série 3, n. 2, dez. 2010. Disponível em: <http://www.scielo.mec.pt/pdf/ref/vserIIIn2/serIIIn2al4.pdf>. Acesso em: 19 out. 2017.

FELGAR, J. A. S. Uma expressão da linguagem numérica. In: KARSCH, U. M. S. (Org.). Envelhecimento com dependência: revelando cuidadores. São Paulo: Educ, 2004, p. 47-85.

FRANKL, V. E. Em busca de sentido: um psicólogo no campo de concentração. 10. ed. rev. São Leopoldo: Sinodal; Petrópolis: Vozes, 1999.

FUNDAÇÃO SISTEMA ESTADUAL DE ANÁLISES DE DADOS (SEADE). Perfil de municípios. São Paulo, 2017. Disponível em: <http://www.imp.seade.gov.br/ frontend/\#/perfil >. Acesso em: 19 abr. 2017.

GAIOLI, C. C. L. O.; FUREGATO, A. R. F.; SANTOS, J. L. F. Perfil de Cuidadores de Idosos com Doença de Alzheimer Associado a Resiliência. Texto Contexto Enfermagem, Florianópolis, v. 21, n. 1, p. 150-157, jan./ mar. 2012. Disponível em: <http://www.scielo.br/pdf/ tce/v21nl/al7v21n1.pdf $>$. Acesso em: 31 out. 2016.

GENET, N. et al. Home care in Europe: a systematic literature review. BMC Health Services Research, Londres, v. 11, n. 207, p. 1-14, 2011. Disponível em: <http://www.biomedcentral.com/1472-6963/11/207>. Acesso em: 30 out. 2013.

GUTIERREZ, L. L. P.; FERNANDES, N. R. M.; MASCARENHAS, M. Caracterização de cuidadores de idosos da região metropolitana de Porto Alegre (RS): perfil do cuidado. Saúde em Debate, Rio de Janeiro, v. 41, n. 114, p. 885-898, jul./set. 2017. Disponível em: $<$ http://docvirt.com/asp/acervo_cebes.asp?Bib=SAUD EDEBATE\&PASTA=V.41\%2C+N.114+-+jul.\%2Fset.\%2F 2017\&pesq $=\& \mathrm{x}=26 \& \mathrm{y}=16>$. Acesso em: 19 out. 2017.

HAYASHI, M. The care of older people in Japan: myths and realities of Family care. History and policy, Londres, jun. 2011. Disponível em: <http://www. 
historyandpolicy.org/policy-papers/papers/the-care-of-older-people-in-japan-myths-and-realities-of-family-care>. Acesso em: 26 out. 2016.

KARSCH, U. M. S. (Org.). Envelhecimento com dependência: revelando cuidadores. São Paulo: Educ, 2004.

LACERDA, M. R. Cuidado domiciliar: em busca da autonomia do indivíduo e da família: na perspectiva da área pública. Ciência \&t Saúde Coletiva, Rio de Janeiro, v. 15, n. 5, p. 2621-2626, ago. 2010. Disponível em: $<$ http://www.scielo.br/pdf/csc/v15n5/v15n5a36.pdf >. Acesso em: 9 ago. 2017.

MELUCCI, A. Por uma sociologia Reflexiva: pesquisa qualitativa e cultura. Petrópolis: Vozes, 2005.

MUNIZ, E. A. et al. Grau de sobrecarga dos cuidadores de idosos atendidos em domicílio pela estratégia Saúde da Família. Saúde em Debate, Rio de Janeiro, v. 40, n. 110, p. 172-182, jul./set. 2016. Disponível em: <http://www.scielo.br/pdf/sdeb/v40n110/0103-1104sdeb-40-110-0172.pdf>. Acesso em: 19 abr. 2017.

ROSA, J. G. Grande Sertão: Veredas. 19. ed. Rio de Janeiro: Nova Fronteira, 2001.

ROSELLÓ, F. T. Antropologia do cuidar. Petrópolis:

Vozes, 2009

TEDESCO, S. H.; SADE, C.; CALIMAN, L. V. A entrevista na pesquisa cartográfica: a experiência do dizer. Fractal Revista de Psicologia, Rio de Janeiro, v. 25, n. 2, p. 299-322, maio 2013. Disponível em: <http://www. scielo.br/pdf/fractal/v25n2/06.pdf >. Acesso em: 21 jun. 2015.

Recebido para publicação em maio de 2017

Versão final em setembro de 2017

Conflito de interesses: inexistente

Suporte financeiro: pesquisa financiada pela Coordenação de

Aperfeiçoamento de Pessoal de Nível Superior (Capes) - Proap

- DS 